\title{
Is there a biology of suicide?
}

\author{
Kevin M Malone
}

Ir J Psych Med 1999; 16(4): 121-122

The importance of a psychiatric disorder in suicidal acts, including suicide, is underscored by the much-replicated finding that about $90 \%$ of completed suicides have a diagnosable Axis I psychiatric disorder at the time of death. ${ }^{1}$

From recent studies in Ireland ${ }^{2}$ and other countries, alcohol abuse/dependence is the most common psychiatric disorder, followed by depression. However, far more people have psychiatric disorders who will never carry out a suicidal act including suicide. This has led researchers to examine factors within the individual that predispose them to suicidal acts during times of stress, such as an Axis I psychiatric episode.

A stress-diathesis (trigger/threshold) model for suicidal acts including suicide has been proposed, whereby a suici$\mathrm{dal}$ act is the result of a combination of a stress (trigger) in a predisposed/vulnerable individual (threshold)., ${ }^{3,4}$.

The first clue that there may be a biological component to the threshold for suicidal acts arose 25 years ago, when the brains and spinal fluid of a small group of psychiatric patients who had completed suicide were studied. They were found to have lower spinal fluid metabolite of the brain neurotransmitter serotonin, regardless of psychiatric diagnosis. ${ }^{5}$ At the time, serotonin was known to be one of the monoamines associated with depression, and low serotonin in suicide was linked with the prevailing monoamine theories of depression. Shortly after this report, further brain studies reported that serotonin-2 receptors in the frontal cortex of the brain were increased in suicide victims. ${ }^{6}$

In anatomical terms, it was known that serotonin was synthesised in the brain stem (the raphe nucleus) and serotonin neurons projected from the brain stem throughout the brain cortex, particularly the medial frontal cortex. As the body routinely compensates for reduced neurotransmitter concentration or availability (or 'signal') by increasing receptor density, increased serotonin receptor populations in suicide victims suggested a biological compensatory mechanism for reduced serotonin.

Since those early reports, 12 of 17 studies on brains of suicide victims have supported these findings. The most recent study identified that not only was serotonin reduced in the brain stem of suicide victims, but that significant alterations were noted within specific regions of the medial prefrontal cortex of the brain. ${ }^{7.8}$ In live patients, reduced serotonin levels have been associated with more lethal suicide attempts, ${ }^{9,10}$ and there is early evidence that serotonin activation may soon be assessable in live patients using brain positron emission tomography. ${ }^{11}$

The frontal cortex of the brain is the most 'recent' evolutionary organ in man, and is known to be closely

Kevin M Malone, MD, MRCPsych, Consultant Psychiatrist/Senior Lecturer, Department of Adult Psychiatry, Mater Hospital, Eccles St, Dublin 7, Ireland.

SUBMITTED: SEPTEMBER 30, 1999. ACCEPTED: NOVEMBER 4, 1999. associated with mood regulation, decision-making and executive reasoning ('will I/won't I, should I/shouldn't I?'). The knowledge that the frontal cortex is rich in serotonin projections from the brain stem led biological suicide researchers to hypothesise that serotonin may be intimately involved with these critical psychological functions.

Data from animal studies also suggested that fluctuations and artificial manipulations of brain serotonin levels and availability of serotonin resulted in alterations in animal mood and behaviour. ${ }^{12}$ It was thus hypothesised that serotonin may be a key neurotransmitter in the regulation of restraint and in the suppression of unwanted impulses associated with executive reasoning.

During a stressful period such as a major psychiatric episode, it is clinically apparent that ideas of hopelessness and that 'life is not worth living' are common. Suicidal ideas occur in most psychiatric conditions. In general, these suicidal ideas are unwanted and the individual activates pathways within brain executive reasoning centres to suppress the unwanted ideas and images of death by suicide. Successful suppression of these unwanted ideas may depend in part on a threshold of brain serotonin neurotransmitter function, in addition to interpersonal and environmental cues promoting life over death by suicide.

Brain serotonin system function is dependent on a varjety of factors. Males have significantly lower serotonin function than females. Serotonin function declines with age. It may be influenced by diet (cholesterol, fatty acids and tryptophan ${ }^{13}$ ) and alcohol. Alcohol in particular appears to affect serotonin neurons in the brain stem of suicide victims, as well as reducing serotonin transporter function within the prefrontal cortex. ${ }^{7.8}$

Given the close association between alcoholism and suicide, apart from the environmental consequences of alcohol abuse and the risk of depression, destruction of inhibitory brain pathways can only increase the risk of suicide secondary to alcohol. The increase in Irish suicide rates, particularly amongst younger males, may in part be explained by the rise in youth alcohol consumption in Ireland and its suggested toxic effects on sensitive brain neurotransmitter pathways, which protect against suicidal impulses in the context of depressive feelings and dysphoria.

Serotonin level regulation is, evidently, at least partially under genetic influence. Genetic variations in the coding for tryptophan hydroxylase (the rate-limiting step in serotonin synthesis) have reportedly been associated with increased expression of suicidal acts. ${ }^{14}$ Brain serotonin levels are also altered by body hormones, particularly the stress hormone cortisol and also by oestrogen across the menstrual cycle in healthy women, ${ }^{\text {ts }}$ and in premenstrual depression. ${ }^{16}$

Ireland has much to offer the international field of suicide research. Well-conducted cross-sectional and longi- 
tudinal clinical and biological studies in representative community populations, which are technically possible in Ireland, are extremely difficult (logistically and financially) to do in Europe and the USA.

Moreover, these studies can lay the platform for intervention, treatment and prevention studies that can be scientifically evaluated, and serve as models for other communities who logistically cannot conduct them. As suicide research intensifies in Ireland in response to the alarming increase in suicide rates particularly, but not exclusively, in younger males, it is important not to neglect research findings from the 'biology of suicide' scientists and to include well-designed biological studies in our Irish suicide research repertoire.

Understanding of the biology of suicide is in its relative infancy, and further discoveries may have important consequences for the pharmacological treatment of suicidal depression. ${ }^{17}$ Perhaps Irish suicide research can make a contribution to this scientific domain.

Kevin M Malone is Principal Investigator of the Ireland North/ South, Urban/Rural Epidemiologic (INSURE) Collaborative Project on Suicidal Behaviour in Major Psychiatric Disorders.

References

1. Isometsa $E$ et al. Mental disorders in young and middle-aged men who commit suicide. BMJ 1995; 310: 1366-7.

2. Foster T, Gillespie K, McClelland R. Mental disorders and suicide in Northern Ireland. Br J Psychiat 1997: 450-2.
3. Mann JJ. The neurobiology of suicide. Nat Med 1998; 4: 25-30. 4. Mann JJ, Waternaux C, Haas GL, Malone KM. Towards a clinical model of suicidal behaviour in psychiatric patients. Am J Psychiat 1999; 156: 181-9. 5. Asberg M, Traskman L, Thoren P. 5-HIAA in the cerebrospinal fluid: a biochemical suicide predictor? Archives of General Psychiat 1976; 33: 1193-7. 6. Stanley M, Mann JJ, Cohen, L. Serotonin and serotonergic receptors in suicide. Annal of the New York Academy of Sciences 1986; 487: 122-7.

7. Arango V, Underwood MD, Gubbi AV, Mann JJ. Localised alterations in preand postsynaptic serotonin binding sites in the ventrolateral prefrontal cortex of suicide victims. Brain Res 1995; 688(1-2): 121-33.

8. Arango V, Underwood MD, Mann JJ. Biologic alterations in the brainstem of suicides. Psychiatr Clin North Am 1997; 20(3): 581-93.

9. Malone KM, Corbitt EM, Li S, Mann JJ. Prolactin response to fenfluramine and suicide attempt lethality in major depression. Br J Psychiat 1996; 168: $324-$ 29.

10. Mann JJ, Malone KM. Cerebrospinal fluid amines and higher lethality suicide attempts in depressed inpatients. Biological Psychiat 1997; 41: 162-71. 11. Mann JJ, Malone KM, Diehl DJ, Perel J, Nichols TE, Mintun MA. PET imaging of serotonin activation effects on prefrontal cortex in healthy volunteers. J Cereb Blood flow and Metabolism 1996; 16: 418-26.

12. Higley JD, Mehlman PT, Higley SB, Fernald B, Vickers J, Lindell SG, Taub $D M$, Suomi SJ, Linnoila M. Excessive mortality in young free-ranging male non-human primates with low cerebrospinal fluid 5 -hydroxyindoleacetic acid concentrations. Arch Gen Psychiatry 1996; 53(6): 537-43.

13. Hibbeln JR, Linnoila M, Umhau JC, Rawlings R, George DT, Salem N Jr Essential fatty acids predict metabolites of serotonin and dopamine in cerebrospinal fluid among healthy control subjects, and early- and late-onset alcoholics. Biol Psychiat 1998; 44(4): 235-42.

14. Mann JJ, Malone KM, Nielsen DA, Goldman D, Erdos J, Gelernter J. A polymorphism of the tryptophan hydroxylase gene appears associated with suicidal behaviour in depressed patients. Am J Psychiat 1997; 154: 1451-3. 15. O'Keane V, O'Hanlon M, Webb M, Dinan T. d-Fenfluramine/prolactin response throughout the menstrual cycle: evidence for an oestrogen-induced alteration. Clinical Endocrinology 1991; 34: 289-92.

16. Fitzgerald M, Malone KM, Li S, Harrison WM, McBride PA, Endicott J Cooper T, Mann JJ. Blunted serotonin response to fenfluramine challenge in premenstrual dysphoric disorder. Am J Psychiat 1997; 154: 556-8.

17. Oquendo MA, Malone KM, Ellis SP, Sackeim HA, Mann JJ. Inadequacy of antidepressant treatment for patients with major depression who are at risk for suicidal behaviour. Am J Psychiat 1999; 156: 190-4

\section{Guidelines for Authors}

The Journal's aim is to publish original scientific contributions in psychiatry, psychological medicine (including surgery and obstetrics), and related basic sciences (neurosciences, biological, psychological, and social seiences). Its scope includes any subspecialties of the above, eg. behavioural pharmacology, biological psychiatry, child and adolescent psychiatry, mental handicap, forensic psychiatry, psychotherapies, psychiatry of old age, epidemiology, rehabilitation, psychometrics, substance misuse, sexual studies, linguistics, and the history, philosophy and economics of psychiatry.

The journal will accept original papers, clinical case reports, brief research reports, review articles, perspective articles, historical papers, editorials, practice reviews (medical audits), letters to the editor and book reviews. Review articles are usually invited. Original data papers receive top priority for speedy publication.

Manuscripts should be prepared in accordance with the guidelines of the International Committee of Medical Journal Editors.' All case reports must have the patients consent before an article can be published. The page following the title page should carry an Abstract followed by a list of three to 10 Key Words or short phrases drawn, if possible, from the medical subject headings (MeSH) list of Index Medicus. The Title, Key Words and Abstract should be chosen to help future literature searchers.

The Abstract, up to 150 words for an unstructured or 250 words for the structured abstract, ${ }^{2}$ should state specifically the main purposes, procedures, findings and conclusions of the study, emphasising what is new or important. For original papers, brief research reports, medical audits and review articles, a structured abstract ${ }^{2}$ is required, using the headings Objectives, Methods, Results (Findings for review articles) and Conclusions. Under the Abstract heading of Method, include wherever applicable the study design, setting, patients/participants (selection criteria, description), interventions, observational and analytical methods and main outcome measures. (For review articles specify the methods of literature search and selection). Under the Abstract heading of Results, give the most important specific data together with their statistical significance.

Timely references should highlight the study's relevance to current research or clinical practice. References to journal articles ${ }^{1.3}$ and to books ${ }^{46}$ illustrate the 'Vancouver' style,' with journal titles abbreviated as in Index Medicus. The Uniform requirements for manuscripts submitted to biomedical journals' has two paragraphs on statistical guidelines.
These have been explained and elaborated by Bailar and Mosteller. ${ }^{3}$

Figures and graphs should be clear and of good quality, and should be accompanied by relevant data to facilitate redrawing where necessary. All materials sent for publication should be accompanied by a covering letter signed by all the authors, and such material will become the property of the journal until, and if, publication is refused. Material so referred should not be sent elsewhere for publication. One copy of the manuscript should be retained by the author(s) for reference, and four copies of the manuscript and covering letter, one of these being the original, should be sent to:

\section{The Editor,}

Irish Journal of Psychological Medicine, 25 Adelaide Street, Dun Laoghaire, Co Dublin.

All contributions are peer-reviewed by three anonymous assessors and, where relevant, by the deputy statistical editor whom authors may contact for help. Assessments will be sent to the corresponding author usually within six weeks. Where revisions are sought prior to publication, authors are advised to return their revision in quadruplicate, incorporating any suggestions which they agree would improve their paper. The covering letter should respond to each comment, numbered, of each assessor, indicating where the revision deals with it, or why the authors disagree or cannot incorporate it. Each assessor will then receive the authors' revision, covering letter and the previous comments of the other assessors. After the assessors' further comments have been received, the senior editors will make the final decision, including priority and time of publication, and the right to style and if necessary shorten material for publication.

References

1. International Committee of Medical Journal Editors. Uniform requirements for manuscripts submitted to biomedical journals. BMJ $1991 ; 302: 338-41$.

2. Haynes RB, Mulrow CD, Huth EJ, Altman DG, Gardner MJ. More information abstracts revisited. Ann Intern Med 1990; 113:69-76.

3. Bailar JC, Mosteller F. Guidelines for statistical reporting in articles for medical journals. Ann Intern Med $1988 \mathrm{Feb} ; 108(2): 266-73$.

4. Daly LE, Bourke GJ, McGilvray J. Interpretation and uses of medical statistics. 4th ed. Oxford: Blackwell Scientific Publications, 1991: 428-31. 5. Gardner MJ, Altman DG, editors. Statistics with confidence - confidence intervals and statistical guidelines. London: British Medical Journal, 1989: 103-5. [Note: British Medical Journal here is the publisher of a book, not the journal BMJ.

6. American Psychiatric Association. Diagnostic and statistical manual of mental disorders. Washington DC: American Psychiatric Association, 1987. 

Narcolepsy. Dosage: Adults: $200-400 \mathrm{mg}$ daily either as two divided doses in the morning and at noon or as a single morning dose according to response. Elderly: Treatment should start at $100 \mathrm{mg}$ daily which may be increased subsequently to the maximum adult daily dose in the absence of renal or hepatic impairment. Severe renal or hepatic impairment: Reduce dose by half (100-200 mg daily). Children: Not recommended. Contra-indications: Pregnancy, lactation, hypersensitivity to modafinil or any excipients used in Provigil. Warnings and precautions: Patients with major anxiety should only receive Provigil treatment in a specialist unit. Patients should be advised to notify their physician if they become or intend to become pregnant during therapy. Blood pressure and heart rate should be monitored in hypertensive patients. Provigil is not recommended in patients with a history of left ventricular hypertrophy or ischaemic ECG changes, chest pain, arrhythmia or other clinically significant manifestations of mitral valve prolapse in association with CNS stimulant use. Studies of modafinil have demonstrated a low potential for dependence although the possibility of this occurring with long-term use cannot be entirely excluded Drug interactions: Induction of cytochrome P-450 isoenzymes has been observed in vitro. contraception, a product containing at least 50 mcg Tricyclic antidepressants - no clinically relevant interaction was seen in a single dose interaction study of Provigil and clomipramine. However, patients receiving such medication should be carefully monitored. Care should be observed with co-administration of anticonvulsant drugs. Side effects: Nervousness, excitation, aggressive tendencies, insomnia, anorexia, headache, CNS stimulation, abdominal pain, dry mouth, palpitation, tachycardia and tremor have been reported. Nausea and gastric discomfort may occur and may improve when tablets are taken with meals. Pruritic skin rashes have been observed occasionally. Buccofacial dyskinesia has been reported very rarely. Marketing authorisation number: PA $827 / 1 / 1$. Marketing authorisation holder: Cephalon UK Ltd., 11/13 Frederick Sanger Road, Surrey Research Park, Guildford, Surrey GU2 5YD, UK. Legal category: POM. Date of preparation: July 1998. Provigil and Cephalon are registered trademarks.

References: 1. Mitler MM. Sleep 1994: 17: S103-S106. 2. Data on file, Cephalon [676]

3. Lin JS et al. Proc Natl Acad Sci USA 1996; 93 (24): 14128-14133. 4. Simon P et al. Eur Neuropsychopharmacol 1995; 5: 509-514

Medical Information Department Freefone no.

1800535669 and e-mail ukmedinfo@cephalon.com

\section{Cephalon}

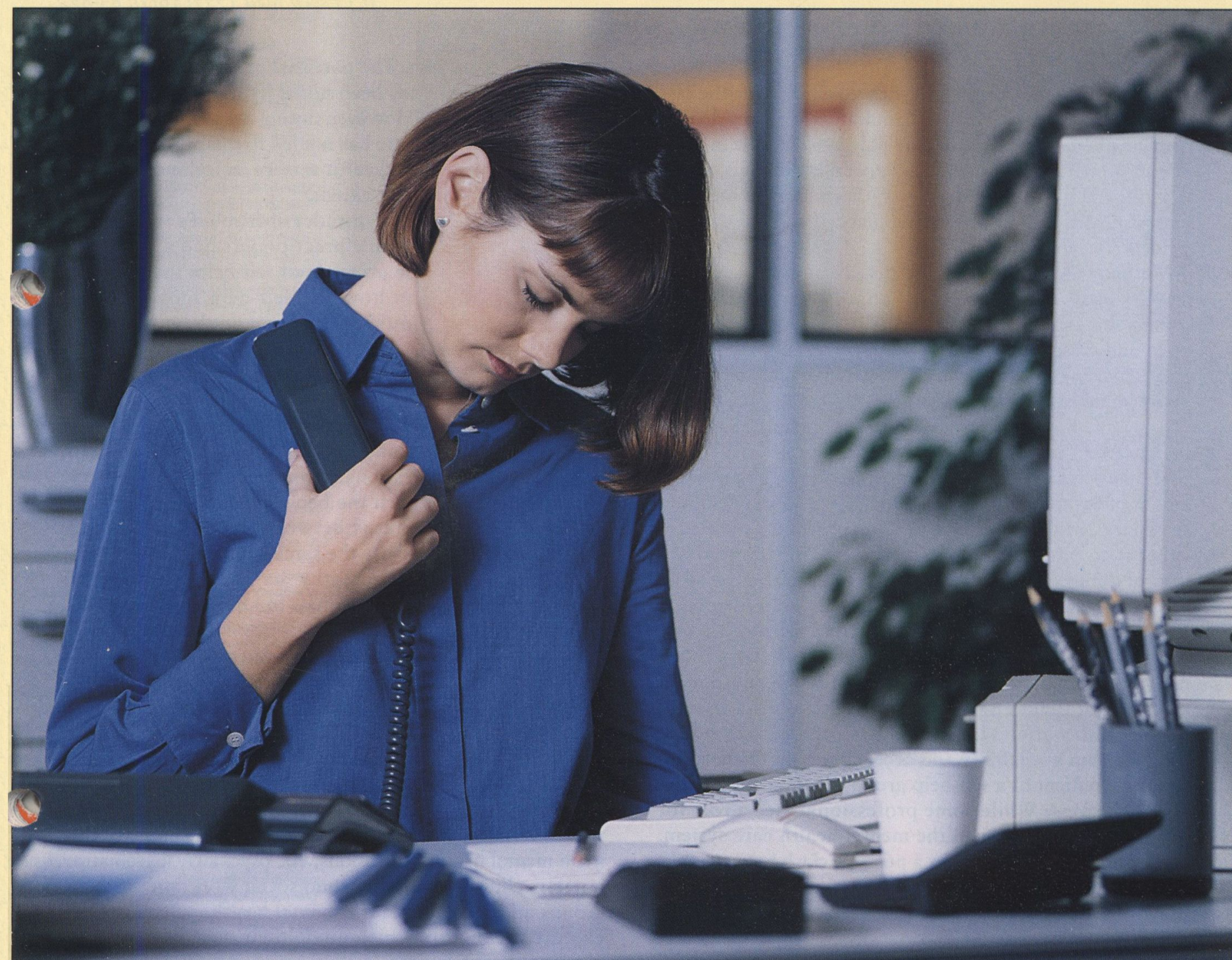

\section{WAKE UP LITTLE SUZIE, WAKE UP}

Excessive sleepiness associated with narcolepsy frequently has a disastrous effect on patients' lives, by impairing their physical, social and emotional well being. Unfortunately, treatment with amphetamines is often associated with a high incidence of unpleasant side effects, which limit their overall benefit.'

Now Provigil (modafinil) - a novel wake promoting agent - offers new advantages in narcolepsy. The clinical efficacy of Provigil has been demonstrated in large controlled clinical studies. In one study, ${ }^{2}$ one in five people with severe narcolepsy reached normal levels of daytime wakefulness while receiving Provigil.

Provigil activates the CNS in a more selective manner than amphetamine and related agents $^{3}$ and differs greatly from this group of drugs in its pharmacology. ${ }^{4}$ Consequently the incidence of amphetamine like side effects is very low.

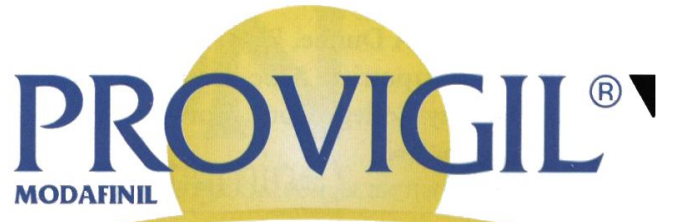

A NOVEL, NON AMPHETAMINE WAKE PROMOTING AGENT 